\title{
Comparison of spirometric results obtained from the sitting and standing position in children participating in an epidemiological study
}

\author{
Grzegorz M. Brożek ${ }^{1}$, Jan E. Zejda ${ }^{1}$, Agnieszka Jarosińska ${ }^{1}$ Agnieszka Idzik ${ }^{1}$, Joshua Lawson², Kamil Barański ${ }^{1}$ \\ ${ }^{1}$ Department of Epidemiology, College of Medicine, Medical University of Silesia, Katowice, Poland \\ ${ }^{2}$ Department of Medicine and Canadian Center for Health and Safety in Agriculture, University of Saskatchewan, Saskatoon, Canada \\ Adv Dermatol Allergol 2018; XXXV (3): 314-316 \\ DOI: https://doi.org/10.5114/ada.2018.75434
}

\begin{abstract}
Introduction: It is recommended that spirometric testing in children be completed while sitting. Our experience indicates that children prefer standing during spirometry.

Aim: We sought to compare spirometric results obtained from the sitting (SIP) and standing (STP) positions.

Material and methods: Two testing sessions were performed in random order (SIP vs. STP: 30-45 min apart) in 118 children (7-13 years), attending one, randomly selected, primary school (response rate: $92 \%)$.

Results: Acceptable quality was found in $77.9 \%$ of STP and $77.1 \%$ of SIP maneuvers. Higher values of spirometric variables on STP, compared to SIP, were obtained for forced vital capacity (FVC) $(2.12 \pm 0.41$ I vs. $2.11 \pm 0.39$ I) and forced expiratory volume in $1 \mathrm{~s}\left(\mathrm{FEV}_{1}\right)(1.78 \pm 0.36$ I vs. $1.77 \pm 0.35 \mathrm{l})$ but the differences were not statistically significant. Relative between-position differences (RBPD) $\leq 5 \%$ were found with the following frequencies: FVC: 56.4\%, $\mathrm{FEV}_{1}:$ 69.2\%, PEF: 21.7\%, and $\mathrm{FEF}_{25-75}: 24.3 \%$. Similar patterns were found for $\mathrm{FEF}_{25}, \mathrm{FEF}_{50}$, and $\mathrm{FEF}_{75}$. Relative between-position differences were related to age in the case of $\operatorname{FEV}_{1}(p=0.005), \operatorname{FEF}_{25}(p=0.02)$, and $\mathrm{FEF}_{25-75}$ $(p=0.01)$ where older children had smaller RBPD. Forced vital capacity RBPD was lower $(p=0.01)$ in subjects with current wheeze; PEF RBPD were lower $(p=0.02)$ in children with asthma.

Conclusions: In epidemiological studies, the position of spirometric testing does not affect the results of lung function assessment.
\end{abstract}

Key words: spirometry, position, children, epidemiology.

\section{Introduction}

According to American Thoracic Society/European Respiratory Society (ATS/ERS) recommendations, it is preferable that spirometric testing in children be completed in the sitting position, for safety reasons [1]. The Global Initiative for Chronic Obstructive Lung Disease (GOLD) guidelines indicate that the standing position involves a risk of syncope [2]. However, no specific data are used to support this view. Our experience with populationbased studies indicates that children feel more comfortable standing during spirometry. There are few published reports which consider "standing results" $[3,4]$.

\section{Aim}

The current study was undertaken to compare spirometric results obtained from the sitting and standing positions in children who were participants of an epidemiological study.

\section{Material and methods}

One randomly selected primary school in the city of Katowice, Poland acted as the sampling frame. All children aged 7-13 years attending the school were invited (response rate was 92\%; study $n=118$ ). Children performed spirometry (EasyOne) at two consecutive testing sessions in random order (sitting vs standing position) 30-45 min apart. Between sessions, children were at rest in the school. The tests were done according to ATS/ ERS recommendations [1]. The quality of the spirometry tests was based on the A-F scale [5, 6]. Grades A, B, and $C$ required a maximum difference between the two best forced expiratory volume in $1 \mathrm{~s}\left(\mathrm{FEV}_{1}\right)$ and forced vital capac- 
ity (FVC) readings of < $100 \mathrm{ml}, 101-150 \mathrm{ml}$, and 151-200 $\mathrm{ml}$ differences, respectively, and represent acceptable quality [5-7]. Analysis involved data from 78 (66.1\%) children who had $\mathrm{A}-\mathrm{C}$ readings in both positions. The following spirometric variables were used in the analysis: FVC, FEV ${ }_{1}$, peak expiratory flow (PEF), forced expiratory flow at $25 \%$ of the pulmonary volume $\left(\mathrm{FEF}_{25}\right)$, forced expiratory flow at $50 \%$ of the pulmonary volume $\left(\mathrm{FEF}_{50}\right)$, forced expiratory flow at $75 \%$ of the pulmonary volume $\left(\mathrm{FEF}_{75}\right)$ and forced expiratory flow at $25-75 \%$ of the pulmonary volume $\left(\mathrm{FEF}_{25-75}\right)$.

Research was performed in accordance with the Declaration of Helsinki and the study protocol was reviewed and approved by the Ethical Review Board at the Medical University of Silesia, Poland (KNW/0022/KB1/5/I/13).

\section{Statistical analysis}

Statistical significance of absolute and relative (\%) between-position differences was assessed using the paired t-test. The effect of sex, age, body mass index (BMI), and chronic respiratory symptoms on the relative betweenposition difference was assessed using the general linear model. The following symptoms were obtained from the questionnaire and included in the separate models: chronic cough (at least 3 months, most days), chest wheeze (last year), attacks of dyspnea (last year). Statistical inference was based on the criterion $p<0.05$.

\section{Results}

The study group was composed of 29 girls and 49 boys. The mean age of subjects was $9.0 \pm 1.6$ years. The frequency of chronic cough was $33.7 \%$, of chest wheeze was $11.6 \%$, and of attacks of dyspnea was $9.0 \%$. No adverse events were observed (Table 1).

On average, higher values of spirometric variables on standing, compared to the sitting position, were obtained for each spirometric variable considered, but the differences were not statistically significant (Table 1). For FVC and $\mathrm{FEV}_{1}$, the majority of children had less than $5 \%$ relative difference between positions (Table 1). Multi-variable analysis showed that the relative (\%) between-position differences were statistically significantly related to age only in the case of $\mathrm{FEV}_{1}(p=0.005), \mathrm{FEF}_{25}(p=0.02)$, $\mathrm{FEF}_{25-75}(p=0.01)$, and marginally in the case of $\mathrm{FEF}_{50}$ $(p=0.08)$ and $\mathrm{FEF}_{75}(p=0.05)$. The associations were negative (older children had smaller relative differences). The relative (\%) between-test differences were not related $(p>0.05)$ to gender and BMI. Only in the case of FVC and PEF were the relative sitting-standing differences statistically significantly related to the symptoms of asthma and were lower in children with the following conditions: FVC differences were lower $(p=0.01)$ in subjects with current wheeze (2.3\%) compared with children without current wheeze (6.1\%); differences in PEF were lower $(p=0.02)$ in children with asthma (3.4\%) than in children without asthma (13.2\%).

\section{Discussion}

Our study showed that the acceptability level of spirometry results was similar in maneuvers performed in the standing and sitting positions (77\%). However, only $62.1 \%$ of children performed acceptable tests on both occasions. Our observations are comparable to results from large epidemiological studies where the percentage of good quality spirometry based on the same criterion varies from $50 \%$ to $80 \%$ [8-10]. While the quality of spirometry is not dependent on position, an interesting issue is why some children were able to perform good spirometry only in one position. Random order of the initial position as well as a similar percentage of good quality spirometry in either position seems to eliminate the influence of the so-called "learning" effect.

Published data are inconsistent and the effect of the position during spirometry on spirometric values was found to be different across the studies [11-19]. Some research has shown that FVC, FEV ${ }_{1}$ and PEFR are significantly higher when obtained in the sitting position [11, 12], while others show that those parameters are higher in the standing position [13-18].

Table 1. Absolute and relative differences in spirometric variables between the standing and sitting position

\begin{tabular}{|c|c|c|c|c|c|c|c|c|c|}
\hline \multirow[t]{2}{*}{ Variable } & \multirow{2}{*}{$\begin{array}{c}\text { Sitting } \\
\text { Mean } \pm \text { SD }\end{array}$} & \multirow{2}{*}{$\begin{array}{c}\text { Standing } \\
\text { Mean } \pm \text { SD }\end{array}$} & \multirow{2}{*}{$\begin{array}{c}\text { Absolute } \\
\text { difference } \\
\text { Mean } \pm \text { SD }\end{array}$} & \multirow[t]{2}{*}{$P$-value* } & \multirow{2}{*}{$\begin{array}{c}\text { Relative } \\
\text { difference } \\
\text { Mean } \% \pm \text { SD }\end{array}$} & \multicolumn{4}{|c|}{ Relative difference standing-sitting } \\
\hline & & & & & & $<5 \%$ & $<10 \%$ & $<15 \%$ & $<20 \%$ \\
\hline FVC $[1]$ & $2.11 \pm 0.39$ & $2.12 \pm 0.41$ & $0.009 \pm 0.04$ & 0.5 & $5.57 \pm 4.62$ & 56.4 & 84.6 & 94.8 & 98.7 \\
\hline $\mathrm{FEV}_{1}[\mathrm{I}]$ & $1.77 \pm 0.35$ & $1.78 \pm 0.37$ & $0.017 \pm 0.13$ & 0.2 & $5.85 \pm 6.63$ & 69.2 & 83.3 & 88.4 & 92.3 \\
\hline PEF $[1]$ & $3.52 \pm 0.85$ & $3.58 \pm 0.85$ & $0.04 \pm 0.53$ & 0.4 & $12.46 \pm 9.51$ & 21.9 & 52.5 & 66.6 & 78.2 \\
\hline $\mathrm{FEF}_{75}[\mathrm{l}]$ & $1.01 \pm 0.44$ & $1.06 \pm 0.41$ & $0.04 \pm 0.35$ & 0.2 & $27.28 \pm 30.70$ & 15.4 & 28.2 & 39.7 & 57.6 \\
\hline $\mathrm{FEF}_{50}[\mathrm{l}]$ & $2.27 \pm 0.68$ & $2.28 \pm 0.71$ & $0.01 \pm 0.51$ & 0.8 & $19.43 \pm 24.94$ & 23.1 & 43.5 & 57.6 & 70.5 \\
\hline $\mathrm{FEF}_{25}[\mathrm{l}]$ & $3.16 \pm 0.90$ & $3.24 \pm 0.85$ & $0.07 \pm 0.61$ & 0.2 & $16.60 \pm 21.62$ & 30.8 & 52.6 & 64.1 & 73.1 \\
\hline $\mathrm{FEF}_{25-75}[\mathrm{l}]$ & $1.92 \pm 0.60$ & $1.95 \pm 0.59$ & $0.02 \pm 0.36$ & 0.5 & $15.98 \pm 16.83$ & 24.4 & 47.4 & 57.6 & 70.5 \\
\hline
\end{tabular}

${ }^{\star}$ Results of paired t-test comparing absolute values. 
In our study, maneuvers in the standing position yielded slightly but not statistically significantly larger values of spirometric variables, particularly for flow rates. It supports the idea that there is no difference of spirometry parameters according to the standing or sitting position [16-18]. In addition to this, the relative differences were mostly less than $5 \%$ for FEV and FVC, which indicates a difference which is not clinically important. While the relative differences were higher for the other spirometric measures, these are to be expected given the increased variability in general of these measures. Also, in an applied epidemiological setting, the common, and more useful, measures considered are the FEV ${ }_{1}$ and FVC.

We found that age was inversely related to the relative percent differences in lung function between positions. This suggests higher consistency in the older age groups and supports the idea that as children age, their developmental ability to perform lung function tests is stronger.

\section{Conclusions}

In epidemiological studies of the respiratory health of children, the position of spirometric testing does not seem to affect the result of lung function assessment, especially in older children, or the safety level of the measuring procedure.

\section{Acknowledgments}

We are grateful to all of the participants for agreeing to take part in our study as well as to Klaudia Glinka, Hanna Motyka, Kamil Baranski and Mateusz Jankowski for technical help in data collection. The study was funded by a scientific grant from the Medical University of Silesia (KNW-1-099/K/3/0).

\section{Conflict of interest}

The authors declare no conflict of interest.

\section{References}

1. Miller MR, Hankinson J, Brusasco V, et al. Standardisation of spirometry. Eur Respir J 2005; 26: 319-38.

2. Spirometry for health care providers. Global Initiative for Chronic Obstructive Lung Disease (GOLD) (last accessed on 10 June 2017). http://www.goldcopd.org/uploads/users/ files/GOLD_Spirometry_2010.pdf.

3. Piccioni P, Borraccino A, Forneris MP, et al. Reference values of forced expiratory volumes and pulmonary flows in 3-6 year children: a cross-sectional study. Respir Res 2007; 8: 14.

4. Alexandraki S, Koutsilieris M, Siafakas N, Katsardis C. Spirometric reference values in Greek children and adolescents. In Vivo 2010; 24: 195-200.

5. Enright PL, Johnson LR, Connett JE, et al. Spirometry in the Lung Health Study. 1. Methods and quality control. Am Rev Respir Dis 1991; 143: 1215-23.
6. Enright PL. How to make sure your spirometry tests are of good quality. Respir Care 2003; 48: 773-6.

7. Ferguson GT, Enright P, Buist AS, Higgins MW. Office spirometry for lung health assessment in adults. A consensus statement from the National Lung Health Education Program. Chest 2000; 117: 1146-61.

8. Enright PL, Skloot GS, Cox-Ganser JM, et al. Quality of spirometry performed by 13,599 participants in the World Trade Center Worker and Volunteer Medical Screening Program. Respir Care 2010; 55: 303-9.

9. Leuppi JD, Miedinger D, Chhajed PN, et al. Quality of spirometry in primary care for case finding of airway obstruction in smokers. Respiration 2010; 79: 469-74.

10. Maio S, Sherrill DL, MacNee W, et al. The European Respiratory Society spirometry tent: a unique form of screening for airway obstruction. Eur Respir J 2012; 39: 1458-67.

11. Patel AK, Thakar HM. Spirometric values in sitting, standing and supine position. J Lung Pulm Respir Res 2015; 2: 00026.

12. Pierson DJ, Dick NP, Petty TL. A comparison of spirometric values with subjects in standing and sitting positions. Chest 1976; 70: 17-20.

13. Hojat B, Mahdi E. Effect of different sitting posture on pulmonary function in students. J Physiol Pathophysiol 2011; 2: 29-33.

14. Gudmundsson G, Cerveny M, Shasby DM. Spirometric values in obese individuals effects of body position. Am J Respir Crit Care Med 1997; 156: 998-9.

15. Townsend MC. Spirometric forced expiratory volumes measured in the standing versus the sitting posture. Am Rev Respir Dis 1984; 130: 123-4.

16. De S. Comparison of spirometric values in sitting versus standing position among patients with obstructive lung function. Indian J Allergy Asthma Immunol 2012; 26: 86-8.

17. McCoy EK, Thomas JL, Sowell RS, et al. An evaluation of peak expiratory flow monitoring: a comparison of sitting versus standing measurements. J Am Board Fam Med 2010; 23: 166-70.

18. Lalloo UG, Becklake MR, Goldsmith CM. Effect of standing versus sitting position on spirometric indices in healthy subjects. Respiration 1991; 58: 122-5.

19. Razi E, Moosavi GA. The effect of positions on spirometric values in obese asthmatic patients. Iran J Allergy Asthma Immunol 2007; 6: 151-4. 